\section{PSICOLOGIA E POLÍTICA SOCIAL: PRÁTICAS NO CONTEXTO DA ASSISTÊNCIA SOCIAL E DA SAÚDE PÚBLICA}

\section{PSYCHOLOGY AND SOCIAL POLICIES: PRACTICES IN CONTEXTS OF SOCIAL ASSISTANCE AND PUBLIC HEALTH}

Erika Andrade de Oliveira, ${ }^{1, *} /$ Edleusa Nery Garrido ${ }^{2}$ Pablo Mateus dos Santos Jacinto ${ }^{3}$

\section{INTRODUÇÃO}

Políticas sociais são definidas por Yamamoto (2007) como estratégias do Estado para resolver problemas sociais particularizados, tais como o combate à desigualdade ou o acesso aos serviços de saúde, e têm como ponto de partida a compreensão dos dispositivos do Estado sobre a chamada “questão social". Sposati et al (2010) definem questão social como uma gama de problemas sociais, políticos e econômicos engendrados pela sociedade capitalista, posição corroborada por Yamamoto (2007) ao referir-se à questão social como a manifestação cotidiana da contradição capitaltrabalho.

Nesse sentido, diante da ausência de estratégias sistêmicas para contrapor o sistema socioeconômico que molda as questões sociais, o Estado estabelece prioridades referentes ao campo social que passam a ser elaboradas a partir de políticas setorizadas. Ao tratar um fenômeno como questão social, o Estado é tensionado a desenvolver estratégias que são executadas de modo fracionado, garantindo, assim, parcelas de direitos como resposta às situações impostas pelo trato com a questão social. É sob essa lógica que se organizam as políticas de Saúde Pública e de Assistência Social, na medida em que o processo de saúde-doença e as desigualdades sociais são compreendidas como questões sociais passíveis de interferência.

\section{RESUMO}

Com vistas a compreender a inserção do psicólogo nas políticas sociais, o artigo buscou refletir sobre a atuação desse profissional nas políticas de Assistência Social e Saúde Pública. Revisou-se publicações de 2001 a 2014, das bases SciELO e LILACS. Selecionou-se 14 produções seguindo os critérios: artigo, em português, com foco na prática de psicólogos nessas duas políticas no Brasil. Formulou-se três categorias de análise: a) Desnivelamento entre formação e inserção no campo de atuação; b) Dificuldades presentes na prática cotidiana; c) Alternativas de trabalho no campo da Assistência Social e da Saúde Pública. Observou-se a existência de dificuldades na atuação por inadequações na formação, sucateamento das políticas sociais e falta de compreensão do profissional acerca do contexto público. Sugere-se a realização de novos estudos, já que com a aprovação da Emenda Constitucional $n^{\circ}$ 95/2016, o país vive uma medida de austeridade que tem gerado impactos nas políticas estudadas.

Palavras-chave: Políticas sociais. Assistência Social. Saúde pública. Psicologia. Revisão Bibliográfica.

\section{ABSTRACT}

In order to understand the psychologist's insertion in social policies, this article intended to discuss the practice of this professional in Social Assistance and Public Health policies. Research published from 2001 to 2014, from the SciELO and LILACS databases, were reviewed. 14 productions were selected following these criteria: being an article, in Portuguese, focusing on the practice of psychologists in these two policies in Brazil Three categories of analysis were formulated: a) Discrepancies between education and insertion in the practical field; b) Difficulties present in daily practice; c) Alternatives to accomplish the practice. It was observed the existence of difficulties in the performance due to inadequate training, low investment on social policies and lack of professional understanding about the public context. It is suggested to carry out further studies on the subject, especially because since the approval of Constitutional Amendment No. 95/2016, the country is experiencing austerity that has impacted the studied policies.

Keywords: Social policies. Social assistance. Public health. Psychology. Bibliographic review.

Submetido em: 1 de jul. 2020

Aceito em: 9 de dez. 2020

${ }^{1}$ Secretaria de Justiça, Direitos Humanos e Desenvolvimento Social - SJDHDS

Salvador, Bahia - Brasil.

${ }^{2}$ Universidade do Estado da Bahia - UNEB, Salvador, Bahia - Brasil.

${ }^{3}$ Centro Universitário Jorge Amado - UNIJORGE, Salvador, Bahia - Brasil.

*E-mail para correspondência: oli_erika@hotmail.com

Rev. ComCiência - dez. 2020, vol. 5, no. 7, p. 57-66 / doi: 10.36112/issn2595-1890.v5.i7.p57-66 
Sobre essa égide, após o período de redemocratização, caracterizado pela intensa mobilização popular e com a instauração da Constituição de 1988, as ações do Estado frente aos direitos fundamentais se expandem e, com isso, se fortalecem e/ou surgem serviços e políticas sociais para abarcar tais demandas. A política pública de Saúde, materializada no Sistema Único de Saúde (SUS), e a política pública de Assistência Social, formalizada no Sistema Único de Assistência Social (SUAS), são, então, configuradas e tornam-se responsáveis por agregar a maior parte dos profissionais de psicologia imersos nesse campo.

Nesse bojo, a Psicologia passa a ser demandada com maior intensidade nesses setores, gerando um campo de atuação que - pela primeira vez - se equipara ao setor privado de atuação (BASTOS; GONDIN, 2010; YAMAMOTO, 2012). Como pode ser ilustrado por Macedo e Dimenstein (2012), estes constatam que em 2012 havia 236.100 profissionais de Psicologia em exercício no Brasil, sendo que pelo menos um quarto deste total atuava nos aparelhos do Estado, distribuídos em todo o território nacional.

Apesar disso, a inserção do psicólogo em novos campos não tem representado necessariamente uma prática nova e diversificada (SILVA; YAMAMOTO, 2013). Entretanto, esse profissional continua exercendo, predominantemente, atividades tradicionais como avaliação psicológica e psicoterapia individual (BASTOS; GONDIN, 2010).

Essas intervenções, apesar da consolidação e da contribuição para o exercício da Psicologia no Brasil, não têm se mostrado suficientes para uma prática condizente com os objetivos das políticas públicas. Nesse cenário, a Psicologia - profissão frequentemente associada à espaços de atuação individualizados e elitizados - se depara com questões como: despreparo da formação, falta de capacitações, precarização dos serviços e do trabalho, pouca disponibilidade de dispositivos efetivos que favoreçam a atuação interdisciplinar, dentre outras demandas (DIMENSTEIN, 2000).

A importância de se buscar compreender a atuação dos psicólogos no contexto das políticas sociais parte, principalmente, do crescimento desses profissionais nesse setor, em comparação com os momentos históricos anteriores à promulgação da Constituição de 1988 (BRASIL, 1988). Diante disso, este estudo teve como objetivo refletir sobre a atuação do psicólogo nos campos da Assistência Social e da Saúde Pública, levando em consideração as dificuldades e os avanços das práticas psicológicas nesses espaços tendo em vista que essas áreas agregam o maior percentual de profissionais de psicologia atuantes no Brasil.

\section{ASPECTOS METODOLÓGICOS}

Este estudo é resultante de uma revisão bibliográfica que, de acordo com Gil (2008), se caracteriza por utilizar como material de análise as publicações de outros autores sobre determinado conteúdo. No presente estudo, foi desenvolvida em duas etapas: construção do banco de dados e construção das categorias temáticas de análise. Para a construção do banco de dados, buscou-se realizar a identificação das bases de dados para coleta, definição dos critérios de inclusão, definição dos descritores de busca e efetivação do levantamento de artigos. Elegeu-se as bases Scientific Electronic Library Online (SCIELO) e Literatura Latino-Americana e do Caribe em Ciências da Saúde (LILACS). Outras bases foram visitadas, porém os resultados obtidos foram repetidos ou traziam materiais fora dos critérios estabelecidos, por isso foram desconsideradas.

Foi, portanto, considerada a literatura produzida entre 2001 e $2014^{4}$, no formato de artigo, em português, que versasse sobre a prática de psicólogos nas políticas de Saúde Pública e Assistência Social no Brasil. Excluiuse trabalhos puramente teóricos e que não atendessem aos critérios mencionados.

Foram adotados os seguintes descritores de busca: Psicologia e Política Social, Compromisso Social e Trabalho do Psicólogo, Psicologia e Saúde Pública, Psicologia e Assistência Social, Psicologia e Questão Social. Do total de 75 artigos encontrados, 39 foram descartados por não se encaixarem na proposta e 14 artigos separados para análise.

No que se refere à construção das categorias de análise, a partir da leitura integral do material e com amparo da Análise de Conteúdo de Bardin (2011), três categorias temáticas foram desenvolvidas, a saber: desnivelamento entre formação e inserção no campo de atuação; dificuldades presentes na prática cotidiana e alternativas de trabalho no campo da Assistência Social e da Saúde Pública.

${ }^{4} \mathrm{O}$ período foi selecionado por ter antecedido a crise política que culminou no impedimento da então presidenta da República, Dilma Rousseff. No governo seguinte, comandado por Michel Temer, foi aprovada a Emenda Constitucional 95 (BRASIL, 2016), que estabelecia um novo Regime Fiscal, adotando uma política de austeridade que congelou por vinte anos os recursos para diversos setores, dentre eles a Saúde e a Assistência Social, gerando impactos na execução dessas políticas. Optou-se, neste estudo, por analisar o cenário anterior à essa medida, diante da maior possibilidade de acesso a estudos sólidos na área. 
3 RESULTADOS E DISCUSSÃO

3.1 DESNIVELAMENTO ENTRE FORMAÇÃO E INSERÇÃO NO CAMPO DE ATUAÇÃO

Essa categoria abarca as considerações feitas pelos autores dos artigos selecionados sobre a relação entre formação e atuação profissional. Fezse uma análise em tópicos do campo da Assistência Social e da Saúde Pública, além de um paralelo entre os pontos de convergência encontrados entre as duas áreas.

A análise dos artigos indica o impacto que a formação exerce na construção do perfil profissional e nas práticas exercidas pelos psicólogos no contexto de atuação em políticas públicas.

\subsubsection{Assistência Social}

Em análise sobre a Psicologia na Assistência Social no Rio Grande do Sul, Motta e Scarparo (2013), constataram resquícios de uma formação tecnicista e fragmentada, aliados à forte influência da psicanálise e sem reflexões sobre os novos desafios necessários no campo da Assistência Social. As autoras observam a necessidade de planejar a ampliação desse referencial teórico junto às demandas existentes no trabalho com a assistência articuladas à mobilização do Conselho Federal de Psicologia na mudança das Diretrizes Curriculares Nacionais (DCN), promovendo um currículo que permita uma atuação mais diversificada.

Essa diversidade na atuação torna-se relevante já que, conforme pontuam Reis e Cabreira (2013), a Psicologia brasileira foi, por muito tempo, direcionada ao atendimento das classes dominantes, excluindo a maioria da população que não possuía re- cursos econômicos para acessar o trabalho desse profissional, o que gerou uma prática pouco alinhada com as questões associadas ao perfil socioeconômico das pessoas em situação de vulnerabilidade e risco, grande parcela da população brasileira e público alvo da Assistência Social.

Com esse histórico, ao atuar com as políticas sociais, o profissional tende a esperar um público homogêneo tal qual aquele que ocupou os consultórios da Psicologia clínica antes da sua popularização (FREIRE; ALBERTO, 2013; SOBRAL; LIMA, 2013). Assim, observa-se a necessidade de uma formação mais ampla, que capacite o profissional para lidar com públicos heterogêneos e a alinhar-se a princípios da prática em políticas públicas, como a atuação interdisciplinar e intersetorial (RIBEIRO et al., 2014; SENRA; GUZZO, 2012).

\section{1. 2 Saúde Pública}

Assim como na Assistência Social, as publicações analisadas demonstram que há um descompasso entre a formação do psicólogo e as exigências presentes no campo da Saúde Pública. Barbosa e Mendes (2005) apontam que as DCN para a formação em Psicologia estão em consonância com o que está preconizado pela estratégia de promoção da saúde, pois valorizam a prática multidisciplinar e intersetorial. Entretanto, na prática, a perspectiva de atuação individual e com características nos moldes dos consultórios privados é vigente. Nesse sentido, as autoras reiteram a importância de uma formação que possibilite ao psicólogo um posicionamento voltado à Saúde Pública que não se resuma à psicoterapia, pois muitas vezes esse modelo não se adequa à demanda.
No mesmo plano, alguns dos autores realçam a importância do conhecimento de conceitos e diretrizes que permeiam o SUS, como: noção de promoção em saúde (BARBOSA; MENDES, 2005); Reforma Sanitária, controle social e SUS no Brasil (CARVALHO et al., 2008; DIMENSTEIN, 2001); historicidade dos modelos explicativos do processo saúdedoença, epidemiologia, funcionamento do SUS em todas as suas dimensões (financiamento, gestão, assistência), modelos técnico-assistenciais em saúde, diagnóstico e planejamento em saúde (ANDRADE; SIMON, 2009; PARISE; ANTONI, 2014).

Dimenstein (2001) aponta ainda para os insuficientes investimentos na formação, capacitação e educação continuada dos trabalhadores de saúde tendo em vista novas práticas sanitárias, além da ausência de integração do aparelho formador com a nova realidade dos serviços públicos de saúde. Ao ignorar tais conhecimentos, o profissional tende a reproduzir práticas que não estão alinhadas com os princípios e as diretrizes do SUS de modo que tem havido o predomínio do modelo individualista, biomédico e hegemônico das práticas psicológicas, como também a psicologização do processo saúde-doença (ANDRADE; SIMON, 2009; OLIVEIRA et al., 2004; RONZANI; RODRIGUES, 2006).

Nepomuceno e Brandão (2011) e Oliveira et al (2005) indicam que o histórico de formação da Psicologia, centrado na perspectiva individual, construiu um saber-fazer ligado à ideologia dominante através de práticas alienadas que não levam em consideração as especificidades culturais dos sujeitos atendidos.

Essa constatação é consonante com o trazido pelos demais artigos analisados nesta categoria da necessi- 
dade de modificação e revisão da formação profissional no nível da graduação e do aperfeiçoamento técnico visando um modelo de atuação mais coerente com a realidade e com as necessidades da Saúde Pública no Brasil, de modo que o profissional compreenda os determinantes sociais relacionados à saúde e intervenha mais efetivamente sobre eles (ANDRADE; SIMON, 2009; ARCHANJO; SCHRAIBER, 2012; RUTSATZ; CÂMARA, 2006).

\subsubsection{Assistência Social e Saúde Pú- blica: um paralelo complementar}

A partir dos artigos analisados, pode-se observar o descompasso existente entre a formação em Psicologia e a inserção desse profissional tanto na Assistência Social quanto na Saúde Pública.

Os elementos comuns encontrados nas produções elencadas demonstram que mesmo em linhas de atuação diferentes e com propostas de intervenção específicas, as dificuldades de inserção do psicólogo são similares e dizem respeito a questões históricas de formação desse profissional no Brasil. O Quadro 1 sintetiza a análise sobre o desnivelamento entre formação e inserção nos referidos campos de atuação.

A formação tecnicista e fragmentada tem sido expressa como problemática no campo da Assistência Social, porém também reverbera na Saúde Pública quando constam nos artigos analisados críticas ao modelo biomédico. Tal apreciação refere-se à compreensão do sujeito centrada na sua natureza orgânica, deixando de lado o aspecto da multidimensionalidade de sua constituição. Questões sociais são postas como secundárias, embora sejam de fundamental análise na prática em políticas públicas, conforme relatado. Daltro e Pondé (2016) apresentam uma crítica ao modelo tecnicista de atuação em Psicologia, pois nas trajetórias formativas corre-se o risco de focar no desenvolvimento de procedimentos técnicos em detrimento de competências atitudinais e conceituais.

Quadro 1 - Desnivelamento entre formação e inserção no campo de atuação do psicólogo

\begin{tabular}{|c|c|}
\hline $\begin{array}{c}\text { Política } \\
\text { social }\end{array}$ & $\begin{array}{l}\text { Desnivelamento entre formação e inserção no } \\
\text { campo de atuacão }\end{array}$ \\
\hline $\begin{array}{l}\text { Assistên- } \\
\text { cia Social }\end{array}$ & $\begin{array}{l}\text { - Resquícios de uma formação tecnicista o } \\
\text { fragmentada; } \\
\text { - Falta de preparo para trabalhar com políticas } \\
\text { públicas; } \\
\text { - Necessidade de uma formação ampla que } \\
\text { trabalhe com interdisciplinaridade e intersetoria- } \\
\text { lidade. }\end{array}$ \\
\hline $\begin{array}{l}\text { Saúde } \\
\text { Pública }\end{array}$ & $\begin{array}{l}\text { - Compreensão do histórico da Saúde Pública o } \\
\text { de seus componentes; } \\
\text { - Necessidade de valorização da perspectiva } \\
\text { intersetorial e interdisciplinar; } \\
\text { - Busca da diversificação da formação para } \\
\text { superação do modelo biomédico; } \\
\text { - Investimento em disciplinas sobre Saúde } \\
\text { pública na graduação e formação complementar }\end{array}$ \\
\hline
\end{tabular}

Fonte: elaborado pelos os autores

Em estudo realizado por Lima e Shcneider (2018), com 18 psicólogos, sobre a atuação desse profissional na Proteção Social Especial a partir do trabalho realizado em seis Centros de Referência Especializado de Assistência Social (CREAS) de Santana Catarina, observa-se que esse é um cenário ainda presente. Os autores pontuam sobre a inexperiência quando da inserção desse profissional na Assistência Social e a desconfiança com que sua atuação é vista pelo conjunto dos demais atores e pela população, que só conhecem o caráter clínico e tradicional da profissão. Esses elementos corroboram para o contexto que foi desenhando nas produções analisadas com publicação até 2014.

\subsection{DIFICULDADES PRESENTES NA PRÁTICA COTIDIANA}

Neste segundo ponto de análise, é possível reforçar a ligação entre for- mação e atuação quando o percurso traçado na primeira impacta significativamente na efetividade da segunda. Além disso, foi possível perceber que a qualidade do serviço prestado pelos profissionais está intimamente condicionada a uma série de fatores externos e estruturais, o que coloca uma gama de desafios e impasses a serem vivenciados por esses trabalhadores em suas rotinas de atuação.

\subsubsection{Dificuldades na Assistência Social}

A atuação da Psicologia não pressupõe apenas uma prática clínica, ainda que tenha sido observado o predomínio desta no escopo de atuação dos psicólogos (FREIRE; ALBERTO, 2013; SENRA; GUZZO, 2012; SOBRAL; LIMA, 2013). O exercício que destoa do paradigma clínico pareceu ser uma dificuldade no estabelecimento dos limites e das características de atuação do assistente social e do psicólogo no campo da Assistência Social (MOTTA; SCARPARO, 2013).

Nesse sentido, é fundamental que a atuação profissional esteja respaldada pelos documentos oficiais, tais como: leis, decretos, portarias, dentre outros marcos regulatórios que orientam o campo. Ribeiro et al. (2014) revelaram que os profissionais da Assistência Social avaliam os documentos oficiais como muito amplos e pouco efetivos como diretrizes de trabalho. Além disso, o artigo aborda os empecilhos que permeiam os fazeres profissionais do psicólogo que, em muitos momentos, apresentam sugestões não condizentes com a real estruturação da rede. Esses posicionamentos são reforçados por Reis e Cabreira (2013) que acrescentam as longas extensões geográficas cujos profissionais devem cobrir em suas áreas de 
abrangência como um fator geralmente desconsiderado nas análises da estruturação do trabalho e da atuação (REIS; CABREIRA, 2013).

Em linhas gerais, os artigos analisados salientaram as dificuldades decorrentes do processo de precarização dos dispositivos da Assistência Social e das relações de trabalho, que são evidenciados pela falta de recursos para a realização de atividades, pela necessidade não atendida de suporte e capacitação, na alta rotatividade entre profissionais, com a escassez de concursos públicos, terceirização, desvio de função e subordinação à gestão pública (FREIRE; ALBERTO, 2013; SENRA; GUZZO, 2012).

Com indícios de poucas modificações, o estudo de Lima e Shcneider (2018) concluiu que ainda persistem os dilemas extensamente debatidos aqui como a precarização dos regimes de trabalho, a alta rotatividade de funcionários, o duplo emprego que caracteriza a fonte de renda da categoria, entre outros elementos que implicam em prejuízos no trabalho social desenvolvido com as famílias e indivíduos. Além disso, as autoras afirmam que esses aspectos incidem negativamente na adesão dos atendidos aos serviços e às atividades propostas e fragilizam a saúde desses trabalhadores.

\subsubsection{Dificuldades na Saúde Pública}

Barbosa e Mendes (2005) observaram que as práticas da Psicologia no SUS pareceram indicar um trabalho heterogêneo, com utilização de diversos modelos de atuação como terapia individual ou em grupo, oficinas terapêuticas, triagem, orientação familiar, entre outras. Revela-se, entretanto, um caráter pouco estruturado e carente de diretrizes específicas e objetivas, demonstrando que as práticas partem mais de uma inclinação profissional que de uma deliberação regimental. Entretanto, Parise e Antoni (2014) revelam que, mesmo quando há premissa legal, os profissionais encontram dificuldades para concretizar a atuação interdisciplinar e intersetorial uma vez que a carência da rede de atenção à Saúde Pública dificulta as ações de encaminhamento e contrarreferência.

Andrade e Simon (2009) verificaram que o tipo de demanda encaminhada aos psicólogos se referia ao atendimento de problemas emocionais e comportamentais,

Sugerindo uma prática ainda pautada no modelo tradicional de enxergar o processo saúde-doença, bem como a ênfase na dimensão psicológica, reduzindo o usuário à dimensão subjetiva ou à doença. Archanjo e Schraiber (2012) demonstraram que, mesmo quando o profissional planeja práticas que rompem com esse modelo, a gestão lhe encaminha demandas que seguem um paradigma da psicologia paliativa e acrítica. Por outro lado, Carvalho et al. (2008) observaram que a noção de cuidado passa a obedecer a um critério técnico, pouco reflexivo, que coloca o usuário no papel de objeto de intervenção e não de sujeito de direitos.

Aspectos relacionados à valorização do trabalho também são pontuados nos estudos, como a ausência de estabilidade profissional e a pressão pelo cumprimento de metas baseadas em fatores quantitativos como número e tempo de atendimento (ARCHANJO; SCHRAIBER, 2012; RUTSATZ; CÂMARA, 2006). Além disso, Dimenstein (2001) verificou que a maioria das profissionais pesquisadas não possuíam pós-graduação, destacando a importância que tem o papel da formação continuada alinhada e estimulada pela gestão da política.
Pode-se constatar que tal perspectiva permanece em voga, conforme trabalho recente de Alves, Bruning e Kohler (2019). As autoras buscaram compreender a atuação do psicólogo inserido no Núcleo de Apoio à Saúde da Família (NASF) na Foz do Vale do Itajaí, em Santa Catarina, por meio da aplicação de entrevista semiestruturada com nove psicólogos atuantes nessa área. Os resultados encontrados fazem ecoar a realidade de outros locais do país sobre as dificuldades desses trabalhadores com a sobrecarga de trabalho, com o planejamento, levantamento e monitoramento das ações realizadas, na compreensão da equipe e dos usuários sobre a atuação do psicólogo e na ausência de suporte para a qualificação do trabalho, fatores esses que incidiam diretamente sobre a saúde e a motivação desses profissionais em seu campo de atuação.

\subsubsection{Assistência Social e Saúde Pú- blica: um paralelo complementar}

Os entraves na formação refletem na construção da prática profissional dos psicólogos. Nesse quesito, a revisão da literatura selecionada indicou que as dificuldades desses profissionais nos dois campos de atuação também convergem. O Quadro 2 a seguir demonstra a síntese dessas dificuldades.

Na Assistência Social, questões como o estabelecimento de limites entre a atuação do psicólogo e do assistente social, a necessidade de mais suporte e capacitação, a precarização do trabalho (alta rotatividade, baixos salários, instabilidade empregatícia), e as práticas hegemonizadas pelo atendimento clínico individual foram trazidos pelos autores como entraves preponderantes (FREIRE; ALBERTO, 2013; MOTTA; SCARPARO, 2013; 
REIS; CABREIRA, 2013; SENRA; GUZZO, 2012; SOBRAL; LIMA, 2013).

\begin{tabular}{|c|c|}
\hline $\begin{array}{c}\text { Política } \\
\text { social }\end{array}$ & $\begin{array}{l}\text { Dificuldades presentes na prática cotidia- } \\
\text { na }\end{array}$ \\
\hline $\begin{array}{l}\text { Assistência } \\
\text { Social }\end{array}$ & $\begin{array}{l}\text { - Ausência de limites entre a atuação do } \\
\text { psicólogo e do assistente social; } \\
\text { - Suporte e capacitação insuficiente; } \\
\text { - Precarização do trabalho (alta rotatividade, } \\
\text { baixos salários, instabilidade empregatícia); } \\
\text { - Atendimento clínico individual hegemôni- } \\
\text { co; } \\
\text { - Fragilidade da rede socioassistencial. }\end{array}$ \\
\hline Saúde & $\begin{array}{l}\text { - Estruturas físicas precarizadas; } \\
\text { - Dificuldades de planejamento e execução } \\
\text { das atividades propostas; } \\
\text { - Prática profissional atrelada ao modelo } \\
\text { biomédico; } \\
\text { - Ausência de reflexão crítica coletiva sobre } \\
\text { as ações efetuadas; } \\
\text { - Dificuldade em estabelecer uma prática } \\
\text { psicológica e de se inserir efetivamente na } \\
\text { equipe multiprofissional (interdisciplinarida- } \\
\text { de e intersetorialidade). }\end{array}$ \\
\hline
\end{tabular}

Fonte: elaborado pelos autores

Por sua vez, no campo da Saúde Pública, foram encontrados pontos de fragilidades como a realização de trabalhos com pouco planejamento e estruturação; práticas profissionais atreladas exclusivamente ao modelo biomédico; ausência de reflexões críticas sobre o trabalho prestado; e dificuldades em estabelecer uma prática psicológica inserida efetivamente na equipe multiprofissional (interdisciplinaridade e intersetorialidade) (ANDRADE; SIMON, 2009; ARCHANJO; SCHRAIBER, 2012; BARBOSA; MENDES, 2005; PARISE; ANTONI; 2014; RUTSATZ; CÂMARA, 2006).

Cintra e Bernardo (2017), em pesquisa de caráter qualitativo a partir da realização de entrevistas abertas com três psicólogos que atuam em Unidades Básicas de Saúde (UBS) de Campinas, apontaram a necessidade de levar em consideração o tempo para a consolidação do manejo técnico e da confiança do psicólogo entre a equipe e com os usuários, bem como para que atividades relevantes possam ser feitas no espaço do trabalho da psicologia uma vez que há a concepção e busca tanto dos profissionais como dos próprios usuários - de que o psicólogo assuma uma posição tradicional ancorada no atendimento clínico individual.

Em publicação recente, Pauli, Traesi e Siqueira (2019) reforçam as discussões trazidas nos artigos analisados na presente produção. Por meio de estudo realizado a partir de entrevista semiestruturada com seis psicólogos de um CREAS em um município do Rio Grande do Sul, as autoras explanaram sobre como a relação de precarização das condições de trabalho via introdução de contratações terceirizadas, alta rotatividade, redução de carga horária para diminuição dos salários, infraestrutura inadequada e gestão ineficiente, interferiam na qualidade dos vínculos estabelecidos com os usuários e com as famílias atendidas, no alcance, efetividade e durabilidade do trabalho executado, na coesão e afinidade das equipes de trabalho. Além disso, apontaram para os adoecimentos de ordem física, emocional e psíquica dos próprios trabalhadores em decorrência dessas condições.

\subsection{ALTERNATIVAS DE TRABA-} LHO NO CAMPO DA ASSISTÊNCIA SOCIAL E DA SAÚDE PÚBLICA

Este item revela que, apesar do cenário encontrado, os trabalhos analisados trazem elementos que indicam a dinamicidade da atuação em políticas públicas na medida em que nada está dado, mas em constante construção. Ainda que a base histórica de formação e consolidação da Psicologia no Brasil, predominantemente centralizada na clínica tradicional, seja presença marcante nas práticas desses profissionais em políticas públicas, é possível perceber que a transição paradigmática está em curso com uma oscilação entre os modelos teóricos metodológicos historicamente consolidados e o modelo psicossocial que se direciona à atuação interdisciplinar, com foco no contexto familiar e comunitário.

\subsubsection{Alternativas de trabalho na Assistência Social}

Apesar das críticas relativas à formação profissional e ao difícil cenário de atuação, os profissionais sugerem alternativas que possibilitam práticas asseguradoras das atividades preconizadas pela política da Assistência Social.

Como caminhos possíveis, foram indicados a construção de uma rede de cooperação com diferentes atores sociais e os exercícios de reflexão direcionados a eliminação da noção de clientelismo, filantropia e benesse que perdura na Assistência Social (MOTTA; SCARPARO, 2013); a instrumentalização das equipes com a criação de referências técnicas para atuação, bem como a criação de um instrumento orientador da atuação que envolva a educação continuada e supervisão, além da necessidade de maior suporte e mais fiscalização por parte da gestão estadual e federal (RIBEIRO et al., 2014)

Além disso, experiências recentes como a descrita por Martins et al (2019) de implementação do Projeto Cinema Perto da Gente, visando o fortalecimento do trabalho social com famílias, indicam a potencialidade que ganha a atuação dos psicólogos quando trabalham os aspectos emocionais e subjetivos dos usuários, através de recursos artísticos e audiovisuais, pois o processo histórico de invisibilidade dos sofrimentos sociais aos quais o público atendido está submerso reflete nas possibilidades de externalização e 
reconhecimento de seus protagonismos como autores de suas próprias histórias.

Atrelado a isso, os profissionais entrevistados pelos autores reforçam a importância desse olhar à subjetividade diante do trabalho em equipe que geralmente está focada na garantia das condições materiais e objetivas dos assistidos, bem como da efetividade quando o trabalho é realizado intersetorialmente a partir de articulações com a Saúde, a Educação e a Cultura, ampliando, portanto, a inserção dos usuários nas políticas públicas e fortalecendo a perspectiva do atendimento integral a esse público.

\subsubsection{Alternativas de trabalho na Saúde Pública}

Assim como nos estudos sobre Assistência Social, esta categoria foi a menos emergente. Entretanto, foi possível identificar práticas adotadas pelos profissionais para superar as dificuldades encontradas.

Archanjo e Schraiber (2012) revelaram que a diversidade colocada pelo serviço público de saúde tensiona o diálogo entre as abordagens teóricas e o desnivelamento entre teoria e prática identificado pelos profissionais. Esse cenário intensifica a necessidade e motivação de busca por formação complementar, o que possibilita abertura para outros campos teóricopráticos.

Rutsatz e Câmara (2006) realizaram estudo no qual questionaram a motivação para os psicólogos atuarem no SUS. A maior parte dos respondentes revelaram ancorar-se em motivações intrínsecas, como a satisfação pessoal estando à frente da estabilidade financeira. Segundo trouxeram os autores, uma trajetória profissional desafiadora gerava nos profissionais interesse em permanecer atuando e encarando as demandas existentes.

Parise e Antoni (2014), sinalizaram para a busca pela interdisciplinaridade como estratégia de superação das dificuldades profissionais. Os autores complementaram que os profissionais demonstram compreender que os saberes específicos da ciência psicológica não são suficientes para abarcar a complexidade das demandas encontradas na Saúde Pública.

Em estudo recente feito por Alves, Brunin e Kohler (2019), os profissionais entrevistados indicaram que a educação permanente e o trabalho em equipe representavam fatores de fortalecimento da atuação do psicólogo na medida em que o primeiro propicia a qualificação técnica e o segundo se configura como um espaço de trocas e vinculação da equipe.

Ainda nessa produção, os participantes pontuaram a alta busca pelos atendimentos individuais em virtude da baixa adesão aos grupos, fato que parece ter correlação com o despreparo dos profissionais para conduzirem esse trabalho e com a expectativa pela equipe e pelos usuários de que o profissional atue com a clínica. Por outro lado, os atendimentos domiciliares, a consulta compartilhada e a compreensão das atribuições de cada ator foram pontuadas como estratégias de trabalho efetivas dentro da Saúde Pública.

\subsubsection{Assistência Social e Saúde Pú- blica: um paralelo complementar}

O Quadro 3 a seguir permite visualizar as alternativas destacadas pelos profissionais nas pesquisas analisadas para lidar com as dificuldades no contexto de atuação.
Quadro 3 - Síntese das alternativas de trabalho na política social

\begin{tabular}{|c|c|}
\hline $\begin{array}{c}\text { Política } \\
\text { social }\end{array}$ & Alternativas de trabalho na política social \\
\hline $\begin{array}{l}\text { Assistên- } \\
\text { cia Social }\end{array}$ & $\begin{array}{l}\text { - Construção de uma rede de interação e coopera- } \\
\text { ção social; } \\
\text { - Criação de novos pressupostos teórico- } \\
\text { metodológicos; } \\
\text { - Desmistificação do caráter assistencialista da } \\
\text { Assistência Social; } \\
\text { - Criação de um instrumento único e de novas } \\
\text { referências técnicas; } \\
\text { - Montagem de uma biblioteca de referência; } \\
\text { - Apoio e maior fiscalização da gestão estadual e } \\
\text { federal; } \\
\text { - Articulação entre os serviços da assistência; }\end{array}$ \\
\hline Saúde & $\begin{array}{l}\text { - Busca de formação complementar; } \\
\text { - Construção de práticas interdisciplinares; } \\
\text { - Ancoragem em motivações intrínsecas para } \\
\text { seguir na atividade; }\end{array}$ \\
\hline
\end{tabular}

Fonte: elaborada pelos autores

Como pode ser visto, ainda são tímidas e genéricas as alternativas propostas para a alteração do cenário encontrado nas produções em análise. Contudo, é possível perceber que esforços estão sendo realizados na tentativa de compreender e investigar a consolidação do compromisso social entre a categoria na prática.

Cintra e Bernardo (2017) a partir do relato dos psicólogos entrevistados sobre a atuação na Atenção Básica dentro do SUS, reforçam os apontamentos em discussão sobre a importância de atividades realizadas para além dos atendimentos clínicos tradicionais, com a execução de trabalhos grupais, de reuniões com escolas e entre profissionais e das visitas domiciliares, para citar alguns exemplos. Além disso, foi possível observar a potência que têm as atividades realizadas fora do espaço dos Centros de Saúde quando se pensa em uma atuação contextualizada, comprometida e horizontal.

Nesse bojo, Lima e Shcneider (2018) destacam que os profissionais entrevistados em seu estudo relatam a importância das orientações tanto da política quanto técnicas, esta última viabilizada pelos Conselhos de Psicologia, para subsidiar a revisão dos 
processos de trabalho e consolidar uma atuação mais qualificada.

Nesse sentido, ambas as políticas sociais abrem espaço para a reestruturação coletiva e a modificação de práticas, pois suas constituições são dinâmicas e ancoradas na historicidade da realidade. No mesmo plano, observa-se que algumas das alternativas de trabalho apresentadas pelos profissionais reforçam a importância do trabalho coletivo e compartilhado, como a necessidade de criar uma rede de interação e cooperação social, bem como de práticas interdisciplinares que promovam a articulação dos serviços com a rede e com a gestão estadual e federal.

\section{CONSIDERAÇÕES FINAIS}

O presente artigo apresentou, por meio da análise da bibliografia, a inserção dos psicólogos nas políticas sociais através da reflexão sobre dois campos de atuação: a Assistência Social e a Saúde Pública. Nesse sentido, o percurso traçado pode demonstrar que há mais semelhanças que diferenças nas realidades descritas e que, apesar de toda a construção para que o lema do compromisso social esteja sedimentado nas concepções e práticas psicológicas, o caminho se encontra em processo de construção, sendo esta produção um material que pode colaborar com reflexões sobre a estruturação e a organização das Diretrizes para o Curso de Psicologia a partir do que tem sido identificado pelos profissionais nos campos de atuação analisados.

Infere-se que, ainda que atrelados às duas áreas amplamente mencionadas aqui, os resultados encontrados neste estudo possivelmente podem ser observados nos mais diversos espaços de inserção da Psicologia em políticas sociais e refletem as contradições exis- tentes no fazer profissional dessa categoria.

Além disso, ressalta-se que a atuação desse profissional está inserida em uma conjuntura complexa e determinada a partir das correlações de forças que se estabelecem por meio das condições históricas e sociais. Essa premissa é fundamental para que haja clareza na compreensão dos limites e possibilidades de avanços nas práticas profissionais da Psicologia, em especial no campo das políticas sociais.

Por fim, apesar do cenário descrito, destaca-se que os textos analisados são advindos de um contexto anterior à promulgação da Emenda Constitucional $\mathrm{n}^{\circ}$ 95, de 15 de dezembro de 2016 (BRASIL, 2016). Essa emenda congelou os gastos públicos por um período de vinte anos, causando mudanças imediatas e a longo prazo que ainda incidem sobre os profissionais que atuam em políticas públicas. Assim, se por um lado o registro aqui realizado serve de base para análises do momento investigado, destaca-se a importância em debater posteriormente os aspectos aqui discutidos de modo a compreender os impactos da promulgação dessa legislação.

\section{REFERÊNCIAS}

\section{ALVES, R. B.; BRUNING, N. O.;} KOHLER, K. C. "O equilibrista": Atuação do psicólogo no NASF no Vale do Itajaí. Psicologia Ciência e Profissão, Brasília, v. 39, e186600, 2019. Disponível em:

<https://www.scielo.br/pdf/pcp/v39/19 82-3703-pcp-39-

e186600.pdf>. Acesso em: 08 jun. 2020.

ANDRADE, M. S. F. J.; SIMON, P. C. Psicologia na atenção primária à saúde: reflexões e implicações práticas. Paideia, v. 19, maio-ago. 2009.
Disponível em:

<http://www.scielo.br/pdf/paideia/v19 n43/04.pdf>. Acesso em: 13 mai. 2020.

ARCHANJO, A. M.; SCHRAIBER, L.B. A atuação dos psicólogos em Unidades Básicas de Saúde na Cidade de São Paulo. Saúde e Sociedade, São Paulo, v. 21, n.2, p.351-363, 2012. Disponível em:

<http://www.scielo.br/pdf/sausoc/v21n 2/a09v21n2.pdf. Acesso em: 20 mar. 2020.

BARBOSA, C. F.; MENDES, I. J. M. Concepção de promoção da saúde de psicólogos no serviço público. Paidéia, São Paulo, v. 15, n. 31, p. 269276, 2005. Disponível em: <https://www.scielo.br/pdf/paideia/v15 n31/14.pdf>. Acesso em: 20 mai. 2020.

BARDIN, L. Análise de conteúdo. São Paulo: Edições 70, 2011.

BASTOS, A. V. B.; GONDIN, S. M. G. (Orgs.). $O$ trabalho do psicólogo no Brasil: um exame à luz das categorias da psicologia organizacional e do trabalho. Porto Alegre: Artmed, 2010. Disponível em:

$<$ http://nacionalarte.com.br/psc/wpcontent/uploads/2017/04/BASTOS-A.V.-B.-GONDIN-S.-M.-G.-O-trabalhodo-psicólogo-no-Brasil.pdf > . Acesso em: 25 abr. 2020.

BRASIL. Constituição da República Federativa do Brasil de 1988. Brasília, 1988. Disponível em: <http://www.planalto.gov.br/ccivil_03/ constituicao/constituicao.htm>. Acesso em: 25 abr. 2020.

\section{BRASIL. Emenda Constitucional $\mathbf{N}^{\circ}$}

95. Altera o Ato das Disposições Constitucionais Transitórias, para instituir o Novo Regime Fiscal, e dá outras providências. Diário Oficial da União. Brasília: DF, 15 de dezembro de 2016. Disponível em:

<http://www.planalto.gov.br/ccivil_03/ constituicao/emendas/emc/emc95.htm>. Acesso em: 15 mai. 2020. 
CARVALHO, B. L et al. Dimensão ética do cuidado em saúde mental na rede pública de serviços. Revista de Saúde Pública, v. 42, n. 4, p. 700-706, 2008. Disponível em:

<https://www.scielo.br/pdf/rsp/v42n4/ 6931.pdf >. Acesso em: 15 mai. 2020.

CINTRA, M. S.; BERNARDO, M. H. Atuação do psicólogo na Atenção Básica do SUS e a Psicologia Social. Psicologia Ciência e Profissão, Brasília, v.37, n. 4, p. 883896, Dec. 2017. Disponível em: <https://www.scielo.br/pdf/pcp/v37n4/ 1414-9893-pcp-37-04-0883.pdf>. Acesso em: 09 jun. 2020.

DALTRO, M. R.; PONDE, M. P. Psicologia como profissão de saúde: relato de um processo de (re)formulação curricular. Psicologia da Educação, São Paulo, n. 42, p. 81-90, jun. 2016. Disponível em:

$<$ http://pepsic.bvsalud.org/pdf/psie/n42 /n42a08.pdf >. Acesso em:

18 mai. 2020.

DIMENSTEIN, M. A cultura profissional do psicólogo e o ideário individualista: implicações para a prática no campo da assistência pública à saúde.

Estudos de Psicologia, no 5, p. 95121, 2000. Disponível em:

<http://www.scielo.br/pdf/epsic/v5n1/a 06v05n1.pdf $>$. Acesso em: 02 mai. 2020 .

DIMENSTEINS, M. O psicólogo e o compromisso social no contexto da Saúde Coletiva. Psicologia em Estudo, Maringá, v. 6, n. 2, p. 57-63, jul./dez. 2001. Disponível em <https://www.scielo.br/pdf/pe/v6n2/v6 n2a08>. Acesso em: 02 mai. 2020.

FREIRE, M. L.; ALBERTO, M. F. P. Centro de referência especializada de assistência social: suporte organizacional para atuação do psicólogo. Cadernos de Psicologia Social do Trabalho, vol. 16, n. 2, p. 167-18, 2013. Disponível em:

<http://pepsic.bvsalud.org/pdf/cpst/v16 n2/a03v16n2.pdf>. Acesso em: 02 jun. 2020.

GIL, Antônio Carlos. Métodos e técnicas de pesquisa social. São Paulo: Atlas, 2008.

LIMA, F. C.; SCHNEIDER, D. R. Características da atuação do psicólogo na Proteção Social Especial em Santa Catarina. Psicologia Ciência e Profissão, Brasília, v. 38, n. 2, p. 347 362, Jun 2018. Disponível em:

<https://www.scielo.br/pdf/pcp/v38n2/ 1982-3703-pcp-38-2-0347.pdf > Acesso em: 05 jun. 2020.

MACEDO, J. P.; DIMENSTEIN, M. O trabalho do psicólogo nas políticas sociais no Brasil. Avances en Psicologia Latinoamericana, ano 30, n.1, p. 182-192, 2012. Disponível em: <http://www.scielo.org.co/pdf/apl/v30 n1/v30n1a15.pdf>. Acesso em: 25 abr. 2020

MARTINS, E. C et al. Cinema perto da gente: arte como estratégia de atuação do psicólogo no CRAS. Psicologia Ciência e Profissão, Brasília, v. 39, e188206, 2019. Disponível em: $<$ https://www.scielo.br/pdf/pcp/v39/19 82-3703-pcp-39-e188206.pdf>. Acesso em: 05 jun. 2020.

MOTTA, R. F; SCARPARO, H. B. K. A Psicologia na assistência social: transitar, travessia. Psicologia \& Sociedade, ano 25, n.1, p. 230-239, 2013. Disponível em:

<https://www.scielo.br/pdf/psoc/v25n1 /25.pdf>. Acesso em: 20 abr. 2020.

NEPOMUCENO, B. L.; BRANDÃO, R. I. Psicólogos na Estratégia de Saúde da Família: caminhos percorridos e desafios a superar. Psicologia Ciência e Profissão, v. 31, ano. 4, p. 762-777, 2011. Disponível em:

<https://www.scielo.br/pdf/pcp/v31n4/ v31n4a08.pdf>. Acesso em: 20 abr. 2020.

OLIVEIRA et. al. A Psicologia, o Sistema Único de Saúde e o Sistema de Informações Ambulatoriais: inovações, propostas e desvirtuamentos.
Interação em Psicologia, Curitiba, p. 273-283, jul./dez., 2005. Disponível em:

$<$ https://revistas.ufpr.br/psicologia/arti cle/view/4790>. Acesso em: 12 mai. 2020.

PARISE, L. F.; ANTONI. D. C. A psicologia na atenção primária à saúde: práticas psicossociais, interdisciplinaridade e intersetorialidade. Clínica \& Cultura, v. III, n. I, p. 71-85, jan./jun. 2014. Disponível em: $<$ http://seer.ufs.br/index.php/clinicaecu ltura/article/view/1991>. Acesso em: 15 mai. 2020.

PAULI, C. G.; TRAESEL, E. S.; SIQUEIRA, A. C. A precarização do trabalho dos psicólogos temporários no CREAS. Psicologia Ciência e Profissão, Brasília, v.39, e188301, 2019. Disponível em:

<https://www.scielo.br/pdf/pcp/v39/19 82-3703-pcp-39-e188301.pdf>. Acesso em: 15 mai. 2020.

REIS, G. R; CABREIRA, L. As políticas públicas e o campo: e o psicólogo com isso? Psicologia Ciência e Profissão, ano 33, (núm. esp.), p. 54-65, 2013. Disponível em:

<https://www.scielo.br/pdf/pcp/v33nsp e/v33speca07.pdf $>$. Acesso em: 18 mai. 2020.

RIBEIRO, A. B et al. Desafio da atuação dos psicólogos nos CREAS do Rio Grande do Norte. Revista de Psicologia, v. 26, n. 2, p. 461-478, maio/ago, 2014. Disponível em:

<https://www.scielo.br/pdf/fractal/v26 n2/1984-0292-fractal-26-02-

00461.pdf>. Acesso em: 18 mai. 2020.

RONZANI, T. M.; RODRIGUES, M. C. O psicólogo na atenção primária à saúde: contribuições, desafios e redirecionamentos. Psicologia Ciência e Profissão, Brasília, v. 26, n. 1, p. 132143, 2006. Disponível em: <http://pepsic.bvsalud.org/pdf/pcp/v26 n1/v26n1a12.pdf $>$. Acesso em: 24 mai. 2020. 
RUTSATZ, S. N.B.; CÂMARA, S. G. O psicólogo na Saúde Pública: trajetórias e percepções na conquista desse espaço. Aletheia, n.23, p.55-64, jan./jun. 2006. Disponível em: http://pepsic.bvsalud.org/pdf/aletheia/n 23/n23a06.pdf. Acesso em: 15 mai. 2020 .

SENRA, G. M. C; GUZZO, L. S. R. Assistência social e psicologia: sobre as tensões e conflitos do psicólogo no cotidiano do serviço público. Psicologia \& Sociedade, v.24, n. 2, p. 293299, 2012. Disponível em: <https://www.scielo.br/pdf/psoc/v24n2 /05.pdf>. Acesso em: 15 mai. 2020.

SILVA, A. C; YAMAMOTO, O. H. As políticas sociais na formação graduada do psicólogo no Piauí. Psicologia Ciência e Profissão, ano 33, p. 824-839, 2013. Disponível em: <https://www.scielo.br/pdf/pcp/v33n4/ v33n4a05.pdf $>$. Acesso em: 05 mai. 2020 .

SOBRAL, M.F.C.; LIMA. M. E. O. Representando as práticas e praticando as representações nos CRAS de Sergipe. Psicologia Ciência e Profissão, ano 33, p. 630-645, 2013. Disponível em:

<https://www.scielo.br/pdf/pcp/v33n3/ v33n3a09.pdf>. Acesso em: 15 mai. 2020.

SPOSATI et al. Assistência na trajetória das políticas sociais brasileiras: uma questão em análise. São Paulo: Cortez, 2010.

YAMAMOTO, O. H. 50 Anos de profissão: Responsabilidade social ou projeto ético político? Psicologia Ciência e Profissão, ano 32, 2012. Disponível em:

<https://www.scielo.br/pdf/pcp/v32nsp e/v32speca02.pdf $>$. Acesso em: 25 abr. 2020.

YAMAMOTO, O. H. Políticas sociais, "terceiro setor" e "compromisso social": perspectivas e limites do trabalho do psicólogo. Psicologia \& Sociedade, Porto Alegre, v. 19, n. 1, abr. 2007. Disponível em: <https://www.scielo.br/pdf/psoc/v19n1 /a05v19n1.pdf $>$. Acesso em: 25 abr.

2020. 